\section{Symposium on Internal Stresses in Metals and} Alloys

Organised by the Institute of Metals in association with the Faraday Sogiety, the Institute of Physics, the Institution of Mhhanical Engineers, the Iron and Steel Institute, Royal Aeronautcalsociety, and held in London on Wednesday and Mursday, 15th and 16th October, 1947. Pp. viii $486+58$ plates. (London: Institute of Metals $\sqrt{348 .)}$ 42s. net.

THESB papers, and the discussions based upon hem, represent a comprehensive survey of the majgr espects of origin, control, measurement and effects df internal stresses. Engineering, physical and $X$-ray methods of measurement are reviewed and ultrasonic methods suggested. Papers on the classifica. tion of stresses and of tessellated stresses are succeeded by reviews of the origin of stresses in copper alloys (leading to stress-corrosion cracking), steel castings and electro-deposited metals. Specific examples are turbine rotors, beams and glassware. Reports are given of recent work on welding stresses, and stresses caused by frictional sliding. A method for estimating macro-stresses in large masses of steel cooled from the austenitic region is described.

Control of stresses by autofrettage, shot peening and pre-stressing (for helical springs) and relief by cold work are considered. A summary is given of the stress-relief treatment of steel castings. The motion of dislocations is discussed briefly. Reviews and examples of internal stresses, also on a microscopic scale, include transformations, diffusion and precipitation, age-hardening and anisotropic thermal expansion. Hairline crack formation in steel is also considered in this section. A photo-elastic technique is described for studying internal stresses. Stress. corrosion cracking, cracking in welded alloy steels and effects in some railway materials are reviewed as macroscopic effects. Recent work is reported on tests for studying the factors affecting cracking in hardened alloy steel plates.

Contributions to the discussions describe many more specific aspects. As a reference book for a large amount of up-to-date information, this report should be of value to metallurgists, engineers and physicists.<smiles>C1=CC2CCCC12</smiles>

Intrduction to Reference Books

By A. D. Roberts. Pp. viii +181 . (London : Library Association, 1948.) 12s. ; to Members of the Association, $9 s$.

7 D HIS book is based on lectures given during the 1945-46 of 1946-47 sessions of the School of Librarianship University College, London. Most of its chatprs pescribe the different types of reference books available such as encyclopædias, dictionaries, ard lirectories; but other reference sources are also covesed, including newspapers and other serials, Government publications, atlases and maps. There is a good chapter on bibliographies, and in the introduction and the concluding chapter Mr. A. D. Roberts gives sound advice on handling inquiries. Overseas publications are well covered; but the book is weak on the scientific and technical side and would be improved by including the wider types of reference works in that field such as Thorpe's "Dictionary of Applied Chemistry", Glazebrook's "Dictionary of Applied Physics" or Hutchinson's "Scientific and Technical Encyclopedia".

With that reservation the book is well designed to serve as an adequate guide to those general works of reference with which a librarian, bibliographer or library student in Great Britain may reasonably be expected to be familiar. Mr. Roberts directs attention to some gaps in our reference material, and, as is proper in a book of this character, he maintains a high standard in his bibliographic references. Author and publisher are to be congratulated on the style and production of a book which should admirably serve its clearly defined purpose. R. BRIGHTMAN

An Introduction to Practical Órganic Chemistry By Prof. R. V. V. Nicholl Second edition. Pp. $x+226$. (Toronto and Nondon: Sir Isaac Pitman and Sons, Ltd., 19.8 15s. net.

RROM the point of view of teaching, chemistry has 1 the disapantage that it is often difficult to provide labordtory exercises for the student which are within ho capacity and yet suffice to illustrate the main point of the subject he is beginning to study. Houber, this can be done in organic chemistry, and in tris book it is done very successfully, the author having included a number of points of modern tech nique and of general interest.

In Part 1 laboratory methods of purification are discussed in considerable detail. The section on distillation, for example, describes an up-to-date fractionating column with variable reflux ratio, and it also gives an account of the vapour-pressure curves of mixtures and of azeotropy.

The main part of the book consists of a series of thirty-one sections which describe experiments in the preparation and examination of representative members of various classes of organic compound with full practical details. The more complex and difficult types of organic reaction are, of course, not included ; but the measurement of such properties as refractive index and optical rotatory power are dealt with, and space has been found for a number of experiments on polymerization and polycondensation reactions, a chromatographic separation of carotene and chlorophyll, and for some representative experiments with fats, sugars and proteins.

Few errors have been noted; but the formula for tryptophan on p. 198 is incorrect, and a statement about the iodoform test for alcohol on p. 205 requires qualification. The book is excellently printed and produced, and it provides the framework for a sound first-year course in the organic chemical laboratory. G. M. B.

Penicillin and other Antibiotics<smiles>C1=[Ge]C=C[Ge]=1</smiles>

By G. W. S. Andrews o hd J. Miller. (Todd Reference Library.) Pp. $16 \theta+4$ plates. (London: Todd Pub. lishing Groyp Etd. 1949.) 7s. 6d. net.

$r$ THIS boof podest in its scope and price, can be recomnderpled to those who are looking for an introducfary lext-book on the antibiotics. It is divided itco four parts entitled respectively : antibio. tica; penicillin; streptomycin and tyrothricin; fudure problems. The general section on antibiotics (thuty-nine pages) deals with antibacterial chemical substances, the sources and properties of antibiotics, and the isolation and identification of antibiotic substances. The sections on penicillin (sixty-five pages), streptomycin (twenty-one pages), and tyrothricin (eight pages) deal with their discovery, chemical and antibacterial properties, production and therapeutic uses. There is also a useful short chapter on the manufacture of penicillin. Future research in antibiotics is described in a little over six pages. A short, but well-chosen, list of references is 